\title{
A novel coordination mode for pentalene in trinuclear chromium complexes
}

\author{
Simon C. Jones, Tony Hascall, Alexander J. Norquist and Dermot O’Hare* \\ Inorganic Chemistry Laboratory, University of Oxford, South Parks Road, Oxford, OX1 3QR, \\ $U K$
}

\section{Supporting Information}

I. Experimental details

1: A solution of $\mathrm{Li}_{2} \mathrm{Pn} \cdot \mathrm{xDME}(\mathrm{x}=1.14)(0.43 \mathrm{~g}, 1.97 \mathrm{mmol})$ in $20 \mathrm{ml} \mathrm{THF}$ was added dropwise to a stirred solution of $\left[\mathrm{Cr}\left(\mathrm{Cp}^{*}\right)(\mu-\mathrm{Cl})\right]_{2}(0.87 \mathrm{~g}, 1.97 \mathrm{mmol})$ in $20 \mathrm{ml}$ THF at $-78^{\circ} \mathrm{C}$, to give a dark solution. This was warmed to room temperature and stirred for $1 \mathrm{hr}$, after which volatiles were removed in vacuo. The dark residue was extracted with toluene $(4 \times 30 \mathrm{ml})$ and filtered through Celite to give a clear dark brown/red solution. Toluene was removed in vacuo and the crude product recrystallized from the minimum volume of $\mathrm{Et}_{2} \mathrm{O}$ at $-35{ }^{\circ} \mathrm{C}$. Yield: $0.74 \mathrm{~g}, 1.06 \mathrm{mmol}, 54 \%$. Analysis found (calculated) for $\mathrm{C}_{39} \mathrm{H}_{54} \mathrm{Cr}_{3} \mathrm{O}(\mathrm{MW}=$ 694.84) (\%): C 65.61 (67.42), H 7.34 (7.83). MS (EI): $m / z=694\left(\mathrm{M}^{+}, 28 \%\right), 663\left(\mathrm{M}^{+}-\mathrm{OMe}\right.$, $10 \%), 476\left(\mathrm{M}^{+}-\mathrm{Cr}-\mathrm{Cp}^{*}-\mathrm{OMe}, 100 \%\right), 289\left(\mathrm{M}^{+}-2 \mathrm{Cr}-2 \mathrm{Cp}^{*}-\mathrm{OMe}, 80 \%\right)$. Infra-red (KBr, selected data): 2950 (m), 2910 (s), 2854 (m), 1560 (m), 1436 (m), 1374 (s), 1262 (m), 1070 (s), $1022(\mathrm{~s}), 806(\mathrm{~s}), 548(\mathrm{~s})$.

2: A solution of $\mathrm{Li}_{2} \mathrm{Pn} \cdot \mathrm{xDEE}(\mathrm{x}=0.35)(0.23 \mathrm{~g}, 1.46 \mathrm{mmol})$ in $20 \mathrm{ml}$ THF was added dropwise to a stirred solution of $\left[\mathrm{Cr}\left(\mathrm{Cp}^{*}\right)(\mu-\mathrm{Cl})\right]_{2}(0.65 \mathrm{~g}, 1.46 \mathrm{mmol})$ in $20 \mathrm{ml} \mathrm{THF}$ at $-78^{\circ} \mathrm{C}$, to give a dark solution. This was warmed to room temperature and stirred for $1 \mathrm{hr}$, after which volatiles were removed in vacuo. The dark residue was extracted with toluene $(4 \times 30 \mathrm{ml})$ and filtered through Celite to give a clear dark brown/red solution. Toluene was removed in vacuo and the crude product recrystallized from the minimum volume of $\mathrm{Et}_{2} \mathrm{O}$ at $-35^{\circ} \mathrm{C}$. Yield: $0.40 \mathrm{~g}, 0.56 \mathrm{mmol}, 38 \%$. Analysis found (calculated) for $\mathrm{C}_{40} \mathrm{H}_{56} \mathrm{Cr}_{3} \mathrm{O}(\mathrm{MW}=$ 708.87) (\%): C 65.18 (67.78), H 7.91 (7.96). MS (EI): $m / z=708\left(\mathrm{M}^{+}, 4 \%\right), 663\left(\mathrm{M}^{+}-\mathrm{OEt}\right.$, 6\%), $476\left(\mathrm{M}^{+}-\mathrm{Cr}-\mathrm{Cp}{ }^{*}-\mathrm{OEt}, 26 \%\right), 289\left(\mathrm{M}^{+}-2 \mathrm{Cr}-2 \mathrm{Cp}{ }^{*}-\mathrm{OEt}, 100 \%\right)$. Infra-red (KBr, selected data): 2956 (m), 2910 (s), 2854 (m), 1560 (w), 1438 (m), 1374 (s), 1260 (m), 1084 (m), 1052 (s), $1022(\mathrm{~s}), 906(\mathrm{~m}), 802(\mathrm{~s}), 554$ (s).

\section{Magnetic measurements}

Solid-state magnetic susceptibility data were obtained using a Quantum Design MPMS-5 SQUID magnetometer. Accurately weighed powdered samples of $c a .0 .05 \mathrm{~g}$ were loaded into gelatine capsules in a glove-box and placed between additional gelatine capsules in a nonmagnetic plastic straw, which was then lowered into the cryostat. The sample is therefore mounted in a weakly diamagnetic medium and no correction need be made for the diamagnetism of the sample-holder. The field independence of the susceptibility data was verified by measuring the susceptibility as a function of field between -5 and $5 \mathrm{~T}$. Data were then measured employing fields of 0.1 and $0.5 \mathrm{~T}$ and were corrected for the inherent diamagnetism of the sample by use of Pascal's constants (O'Conner, C. J. Prog. Inorg. Chem. 1982, 29, 203-283). The diamagnetic corrections applied had value $450 \times 10^{-6} \mathrm{~cm}^{3} \mathrm{~mol}^{-1}$ and $464 \times 10^{-6} \mathrm{~cm}^{3} \mathrm{~mol}^{-1}$ for 1 and 2 respectively. 